\title{
Validation of the Gratitude/Awe Questionnaire and Its Association with Disposition of Gratefulness
}

\author{
Arndt Büssing ${ }^{1,2, *(\mathbb{D})}$, Daniela R. Recchia ${ }^{1}$ (1) and Klaus Baumann ${ }^{2,3}$ (D) \\ 1 Professorship Quality of Life, Spirituality and Coping, Faculty of Heath, Witten/Herdecke University, \\ 583131 Herdecke, Germany; Daniela.RodriguesRecchia@uni-wh.de \\ 2 IUNCTUS-Competence Center for Christian Spirituality, Philosophical-Theological Academy, \\ 48149 Münster, Germany; klaus.baumann@theol.uni-freiburg.de \\ 3 Caritas Science and Christian Social Work, Faculty of Theology, Albert-Ludwig University, Freiburg, \\ 79085 Freiburg im Breisgau, Germany \\ * Correspondence: Arndt.Buessing@uni-wh.de; Tel.: +49-2330-623246
}

Received: 13 March 2018; Accepted: 3 April 2018; Published: 8 April 2018

\begin{abstract}
Self-transcendent feelings such as gratitude, compassion, and awe are highly relevant for human societies. So far, empirical research has focused more on the relational aspects of these feelings (concrete persons), and less on the spiritual aspects referring to the Sacred in a person's life. We intended to validate an extended version of the former three-item Gratitude/Awe scale. This extended scale was designed with a focus on the experiential aspects of being moved and touched by certain moments and places/nature, on related reactions of pausing with daily activities, and on the subsequent feelings of awe and gratitude. Enrolling 183 test persons (67\% women; 59\% with a Christian confession) in a cross-sectional study, we can confirm that the seven-item Gratitude/Awe scale (GrAw-7) has good psychometric properties (Cronbach's alpha $=0.82)$ and moderate correlation $(\mathrm{r}=0.42)$ with grateful disposition (GQ-6 questionnaire). Structured equation modeling (SEM) confirmed that both constructs, although moderately related, are different. While Gratitude/Awe was best predicted by the frequency of meditation practice, a grateful disposition was best predicted by the frequency of praying and by general life satisfaction. The GrAw-7 scale is not contaminated with specific religious topics or quality of life issues, and can be easily implemented in larger studies.
\end{abstract}

Keywords: awe; gratitude; spirituality; validation; questionnaire

\section{Introduction}

Self-transcendent feelings such as gratitude, compassion, and awe (Stellar et al. 2017) may have an influence on the social behavior of individuals and social groups. In their review, Stellar et al. (2017) argued that "self-transcendent emotions help individuals form enduring commitments to kin, nonkin, and social collectives". This perspective emphasizes that they are highly relevant for human societies, and empirical research so far focuses much more on the relational aspects than on the 'self-transcendent' (spiritual) aspects referring to the Sacred in a person's life.

There is currently a debate in philosophical literature as to what exactly constitutes an emotion, and whether or not feelings and emotions are different (Whiting 2011). The terms feelings and emotions are often used interchangeably, but-from a psychological point of view-they are different (Pettinelli 2014) and they arise in different areas of the brain. Feelings can be seen as the mind's interpretations of bodily perceptions and emotions (which arise in the amygdala). Thus, it is difficult to differentiate whether gratitude and awe are emotional perceptions or feelings.

Emmons and Crumpler stated that gratitude is regarded as an "emotional state and an attitude toward life that is a source of human strength in enhancing one's personal and relational wellbeing" 
(Emmons and Crumpler 2000) and is thus an essential dimension of a person's subjective quality of life (Hill and Allemand 2011). Gratefulness as a trait or disposition can be the result of positive experiences (in the past and in the present) and is thus associated with pleasant feelings. Moreover, it can enable the perception of positive experiences in the future and may thus be related to confidence and hope. In this sense, it is a basic human attitude that one's existence (one's coming, being, and remaining in existence) is not a result of one's achievements, but rather "thanks to" others or one other. Such an attitude of gratitude strengthens the conviction that hope, with regard to an uncertain future and trust for the present, is not illusory (Häußling 1988). Gratitude may also arise as the result of the kindness a person receives from a donor and thus requires an interpersonal context (Algoe and Haidt 2009), and is in this case a positive feeling. McCullough et al. (2002) found that a 'grateful disposition' (as measured with the 6-item form of the Gratitude Questionnaire [GQ-6]) is strongly related to life satisfaction, happiness, hope, and optimism. With respect to indicators of spirituality, there were only some weak correlations between a gratitude disposition with spiritual transcendence, self-transcendence, personal relationship with God, etc. (McCullough et al. 2002). Among personality traits, self-rated agreeableness was related best.

In contrast to gratitude, feelings of awe may occur in specific situations of wondering astonishment and admiration when facing breathtaking landscapes, experiencing mystical experiences, etc. (Keltner and Haidt 2003; Pearsall 2007). Because they are already the mind's 'interpretations' of these perceptions, one could argue that awe is not an emotion but a feeling. Nevertheless, Shiota et al. (2007) defined awe as an "emotional response to perceptually vast stimuli that overwhelm current mental structures, yet facilitate attempts at accommodation". Fagley (2012) argued that awe is an aspect of appreciation which refers to "feeling a deep emotional, spiritual, or transcendental connection to something". It is more than, and different from, a trembling feeling and fascinated astonishment (in the sense of Otto's "mysterium tremendum et fascinosum"). Rather, it implies being attracted to, and shying away from the sublime; both loving trust and humble dread (Wisse 1988). There is not necessarily a specific interpersonal context, but "situational appraisals that facilitate gratitude", as Algoe and Stanton (2012) suggested. These perceptions make persons stop in their activities, and they may assume that time 'stands still' in these moments. Feelings of awe can be matter of a spiritual experience and/or the subjective perception of the transcendent, and may therefore result in feelings of gratitude towards life in general, distinct persons, and towards the numinous. In fact, awe is a perception which is strongly associated with feelings of gratitude $(r=0.59)$, but only weakly associated with the general experience of beauty in life $(r=0.30)$, whilein contrast gratitude was strongly related to the experience of beauty in life $(r=0.51)$ (Büssing et al. 2014). This indicates that these feelings are related, but their underlying processes and directions may be distinct.

These perceptions of awe and gratitude can be measured in a standardized way with the three-item subscale on "Gratitude/Awe" (Cronbach's alpha = 0.77) of the SpREUK-P questionnaire (which addresses the frequency of spiritual/religious, existential, and prosocial-humanistic practices) (Büssing et al. 2005, 2012). In persons with multiple sclerosis and psychiatric disorders, this scale was found to be best related to engagement in religious practices $(r=0.48)$ and prosocial-humanistic practices ( $r=0.41$ ) (Büssing et al. 2014). It was concluded that "Gratitude/Awe could be regarded as a life orientation towards noticing and appreciating the positive in life-despite the symptoms of disease" (Büssing et al. 2014). In Catholic priests, the 3-item scale "Gratitude/Awe" was best related to the perception of the Sacred in their life (Daily Spiritual Experience Scale, DSES-6: $r=0.43$ ), with prosocial-humanistic practices $(r=0.41)$, and with life satisfaction (Satisfaction with Life Scale, SWLS: $r=0.36$ ), while in non-ordained Catholic pastoral workers the correlations between "Gratitude/ Awe" and transcendence perception $(r=0.36)$, prosocial-humanistic practices $(r=0.39)$, and life satisfaction $(r=0.24)$ were less pronounced (Büssing et al. 2017). The association with the perception of the Sacred in life is of particular relevance as it indicates that these feelings of awe and gratitude may arise because a person has a distinct state of mindful awareness or a disposition of openness towards the Sacred in 
the daily life concerns rather than being a matter of wellbeing or satisfaction with different aspects of life.

To clarify this, we decided to extend the conceptual framework of SpREUK-P's "Gratitude/Awe" subscale and develop a discrete scale with a clear focus on the experiential aspects of being moved and touched by certain moments and places/nature, on related reactions of pausing with daily activities, and on the subsequent feelings of awe and gratitude. The intention was to operationalize the reality when individuals give room for the experience of such spiritual moments of pausing for a moment, moments of reflection, and encounters with the Sacred wherever it is. These perceptions operationalized in the extended "Gratitude/Awe" questionnaire are thus suggested to represent states of mindful awareness rather than the direct reactions of gratefulness in response to the kindness of concrete persons. Therefore, these feelings are assumed not to be strongly related with wellbeing or general satisfaction with life. When these feelings are in fact influenced by a person's spirituality, then one would expect a positive association with indicators of spirituality such as praying or meditation. In contrast, health behaviors such as smoking, alcohol consumption, or sporting activities are suggested to be unrelated to perceptions of gratitude and awe. Further, these feelings of gratitude and awe are assumed to be related to a 'grateful disposition', but nevertheless as conceptually distinct.

Therefore, we intended (1) to validate an extended version of the "Gratitude/Awe" scale with respect to its factorial structure and internal consistency; (2) to analyze correlations with 'grateful disposition'; and (3) to analyze correlations with wellbeing and life satisfaction on the one hand, and praying/meditation and health behaviors on the other.

\section{Material and Methods}

\subsection{Enrolled Persons}

For the process of validation, we enrolled a heterogeneous sample of participants among students, pastoral professionals, Caritas workers, medical professionals, etc. acquired via snowball sampling in research and private networks. The resulting sample should be regarded as a convenience sample.

The first page of the questionnaire holds information about the purpose of the study (which did not ask for names, initials, or location), and an assertion that confidentiality and anonymity is guaranteed. By filling in the German language questionnaire and sending it back to the study team, participants agreed that their data would be treated anonymously.

\subsection{Measures}

\subsubsection{Gratitude and Awe (GrAw-7)}

The generic SpREUK-P ( $\mathrm{P}$-practices module) questionnaire contains the three-item subscale on "Gratitude/Awe" (Cronbach's alpha $=0.77$ ) addressing feelings of gratitude, reverence/awe, and experiencing the beauty in life (Büssing et al. 2005, 2012). These items were supplemented by four additional items, i.e., "I stop and then think of so many things for which I'm really grateful", "I stop and am captivated by the beauty of nature", "I pause and stay spellbound at the moment", and "In certain places, I become very quiet and devout". Thus, gratitude and awe operationalized in this way are matter of an 'emotional' reaction towards an immediate and 'captive' experience, and not a reaction in response to a person's benevolence, and further not necessarily a matter of a 'grateful disposition'. All items were scored on a four-point scale (0—never; 1—seldom; 2—often; 3-regularly). The resulting scores were sum scores ranging from 0 to 21 .

\subsubsection{Dispositional Gratitude (GQ-6)}

To measure gratitude in daily life, we used the Gratitude Questionnaire-Six Item Form (GQ-6) (McCullough et al. 2002). This instrument addresses an affective trait in terms of a 'disposition toward gratitude' rather than a mood state or an emotion. This disposition is defined "as a generalized tendency 
to recognize and respond with grateful emotion to the roles of other people's benevolence in the positive experiences and outcomes that one obtains" (McCullough et al. 2002, p. 112). Representative items are "I have so much in life for which to be thankful" or "I am grateful to a wide variety of people". Internal consistency of the GQ-6 is good with Cronbach's alpha $=0.82$ (McCullough et al. 2002). The six items are scored on a seven-point scale from strong disagreement (1) to strong agreement (7); two items had a reverse coding.

\subsubsection{Life Satisfaction (BMLSS-10)}

Life satisfaction was measured using the Brief Multidimensional Life Satisfaction Scale (BMLSS; alpha $=0.87$ ) (Büssing et al. 2009). The items address intrinsic (myself, life in general), social (friendships, family life), external (work situation, where I live), and prospective (financial situation, future prospects) dimensions of life satisfaction, as well as satisfaction with the individual's abilities to manage daily life concerns and satisfaction with their health. Each of these 10 items was introduced by the sentence 'I would describe my level of satisfaction as ... ', and they were scored on a seven-point scale ranging from dissatisfaction (0) to satisfaction (6). The mean scores were referred to a $100 \%$ level.

\subsubsection{Wellbeing (WHO-5)}

The WHO-Five Wellbeing Index (WHO-5) measures wellbeing instead of the absence of distress (Bech et al. 2003). Representative items are "I have felt cheerful and in good spirits" or "My daily life has been filled with things that interest me". Respondents assess how often they had the respective feelings within the last two weeks, ranging from at never (0) to all of the time (5). Here we report the sum scores.

\subsubsection{Health Behaviors and Indicators of Spirituality}

We measured the frequency of health behaviors such as smoking (never, 1-10 per day, 10-20 per day, $>20$ per day), alcohol consumption (never, $1 \times$ per month, $2-3 \times$ per month, $1-2 \times$ per week, several times per week), sporting activities (never, $1 \times$ per month, $2-3 \times$ per month, $1-2 \times$ per week, several times per week), and indicators of spirituality such as meditation (never, at least once per month, at least once per week, several times per week) and praying (never, at least once per month, at least once per week, several times per week) using single items.

\subsection{Statistical Analyses}

Descriptive statistics, internal consistency (Cronbach's coefficient $\alpha$ ), and factor analyses (principal component analysis using Varimax rotation with Kaiser's normalization) as well as analyses of variance (ANOVA) and first order correlations analyses were computed with SPSS 23.0.

To confirm the structure found by exploratory factor analysis, we performed a structured equation model (SEM) using the Lavaan packages of software R. This methodology involves many techniques such as multiple regression models, analysis of variance, confirmatory factor analysis, correlation analysis, etc. With SEM one could determine the meaningful relationships between variables, since the parameter estimates deliver the best scenario for the covariance matrix; the better the model goodness of fit, the better the matrix is. The goodness of fit statistics used to evaluate the model included the root mean square error (RMSEA), which should be $\leq 0.05$; the root mean square residual (RMSR), which should be $\leq 0.06$; the comparative fit index (CFI), which should be $\geq 0.95$; and the Tucker-Lewis index (TLI), which should be $\geq 0.95$.

Given the exploratory character of this study, the significance level of ANOVA and correlation analyses were set at $p<0.01$. With respect to classifying the strength of the observed correlations, we regarded $r>0.5$ as a strong correlation, an $r$ between 0.3 and 0.5 as a moderate correlation, an $r$ between 0.2 and 0.3 as a weak correlation, and $r<0.2$ as negligible or no correlation. 


\section{Results}

\subsection{Participants}

As shown in Table 1, among the 183 enrolled persons, women were predominant (67\%). Also, most participants had a high school education (77\%). Christian confessions were predominant (59\%); $17 \%$ identified with other religious denominations, and $24 \%$ stated that they had no religious affiliation.

Table 1. Description of the sample $(N=183)$.

\begin{tabular}{cc}
\hline & Scores \\
\hline Age (years) (Mean \pm SD) & $51.8 \pm 15.5$ \\
\hline Gender (\%) & 67.5 \\
Women & 33.0 \\
Men & \\
Educational level (\%) & 21.5 \\
Secondary school (Haupt-/Realschule) & 77.3 \\
High school (Gymnasium) & 1.1 \\
other & \\
\hline Religious denomination (\%) & 39.8 \\
Catholic & 19.3 \\
Protestant & 16.6 \\
Other & 24.3 \\
None &
\end{tabular}

\subsection{Reliability and Factor Analysis of the Gratitude/Awe Questionnaire}

Explorative Factor analysis of the seven items revealed a Kaiser-Mayer-Olkin value of 0.83, which, as a measure for the degree of common variance, indicating the item pool's suitability for statistical investigation by means of principal component factor analysis. Exploratory factor analysis pointed to one single main factor (eigenvalue 3.4) which accounted for $48 \%$ of variance (Table 2 ). Internal consistency of the seven-item scale $(\mathrm{GrAw}-7)$ was good (Cronbach's alpha $=0.82)$.

Table 2. Reliability and factorial structure.

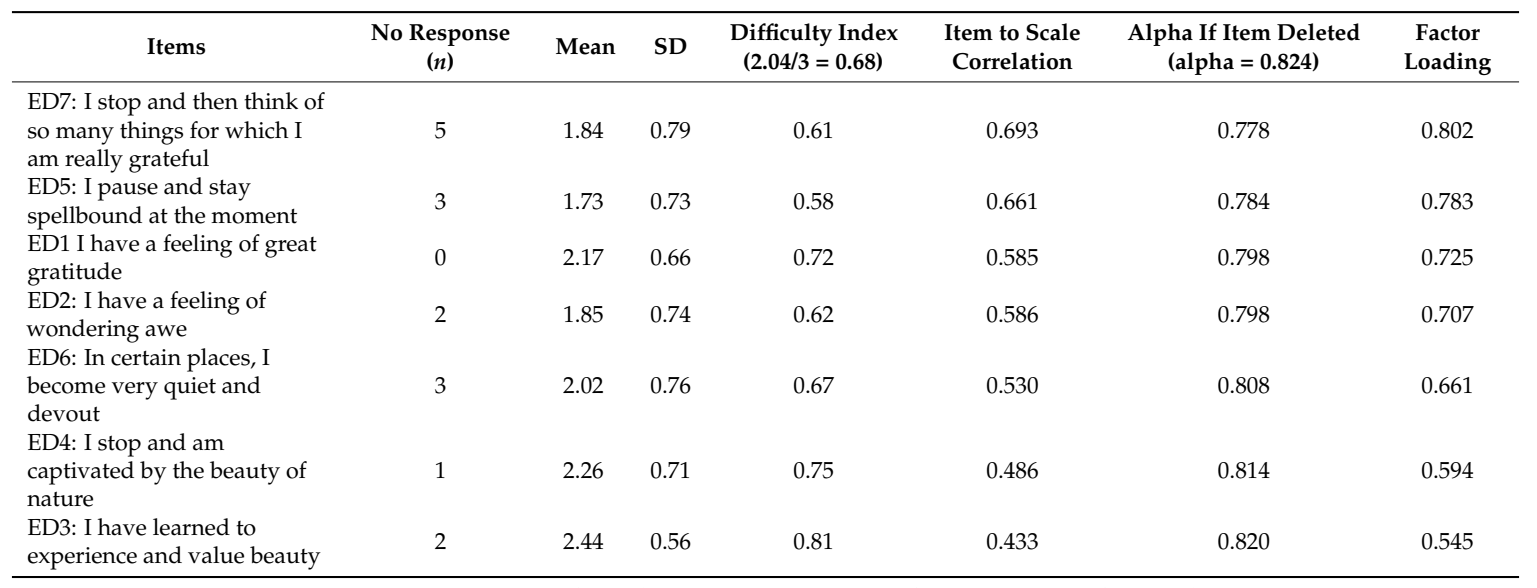

Main component analysis (Variamax rotation with Kaiser normalization).

The difficulty index (mean value 2.04/3) of these items was 0.68; all items were in the acceptable range from 0.2 to 0.8 (Table 2). This means that there were no ceiling or bottom effects in the responses. While all responded to item ED1, a maximum of 3\% of participants did not respond to item ED7 (Table 2).

The statement that one has "learned to experience and value beauty" scored highest, followed by "I stop and am captivated by the beauty of nature"; the lowest scores were found for staying "spellbound at the moment" (Table 2). 


\subsection{Structured Equation Model}

To validate the instrument's structure found by exploratory factor analysis, we performed structured equation modeling (SEM). This method is a comprehensive methodology which involves techniques such as multiple regression models, analyses of variance, confirmatory factor analysis, correlation analysis, etc.

SEM was adjusted as a validation of the previous factor structure with the GrAw-7 items. This model presented good fit statistics and a Cronbach's alpha of 0.82 (Figure 1).

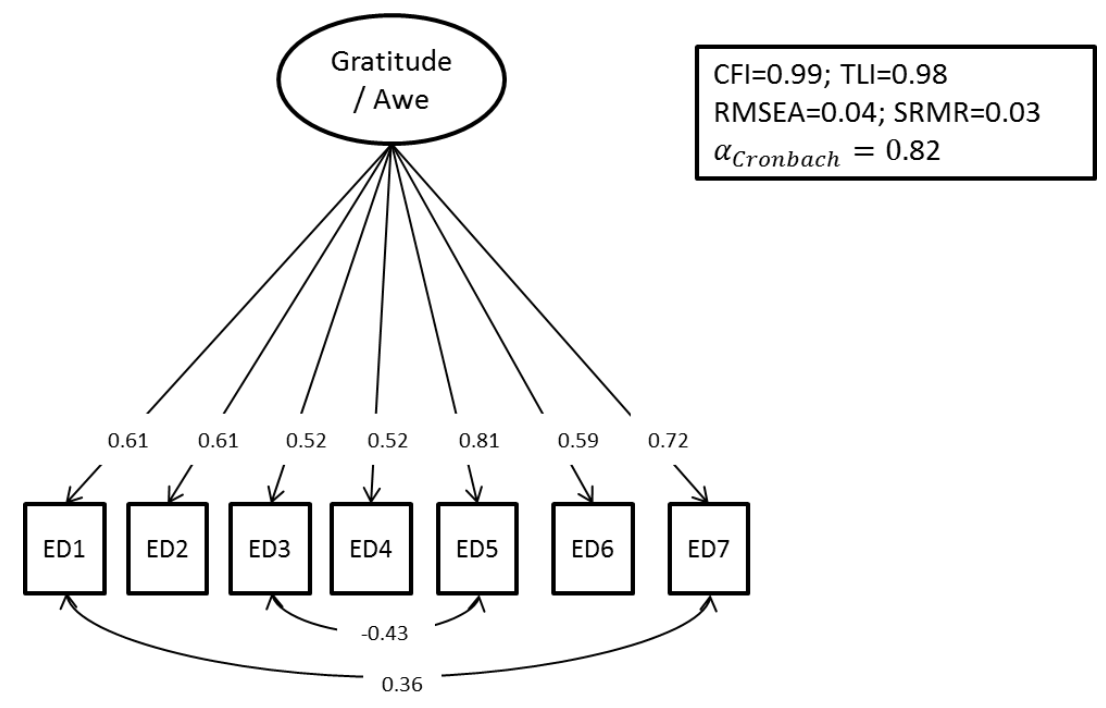

Figure 1. SEM for Gratitude/ Awe (GrAw-7).

We also tested a model that includes the both the GrAw-7 and GQ-6 constructs (Figure 2). Here we found some weak correlations between the single items. Although all four fit measures were very good, the total Cronbach's alpha was at the minimum accepted value $(=0.59)$. This would underline that both instruments should be seen as independent measures.

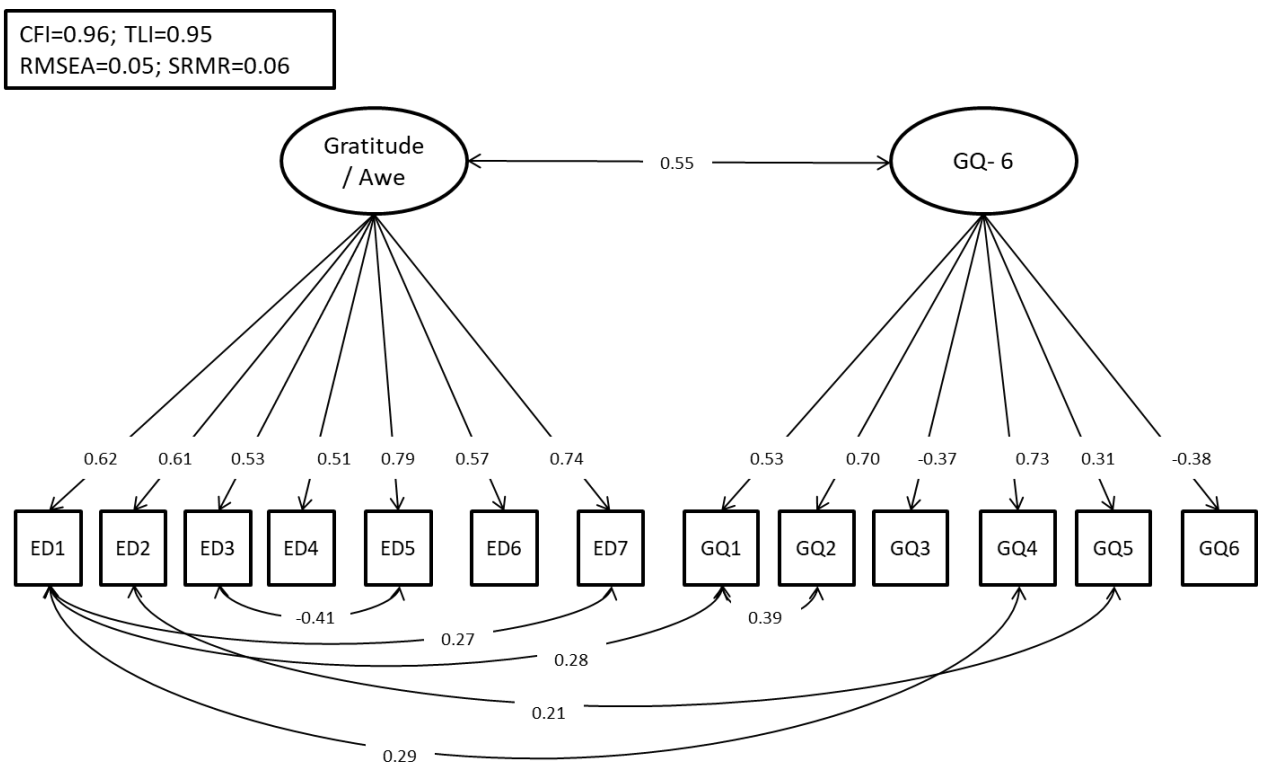

Figure 2. SEM for Gratitude/Awe (GrAw-7) and gratitude disposition (GQ-6). Values on arrows between items (in boxes) and factors (in circles) represent loadings, while items between boxes and circles, respectively, represent correlations. 


\subsection{Expression of Gratitude/Awe Scores in the Sample}

The mean GrAw-7 sum score was $14.1 \pm 3.5$ (range: 5 to $21 ; 25 \%$ quartile $12.0 ; 75 \%$ quartile 16 ). The scores showed nearly normal distribution (Skewness 0.09 with standard error 0.18 , Kurtosis -0.24 with standard error 0.36 ); $7 \%$ of persons reached the maximal score of 21.

There were no significant gender-related differences for GrAw-7 $(F=1.95)$ and GQ-6 $(F=0.76)$ scores in the sample (data not shown). However, age showed a weak positive association with GrAw-7 but not with GQ-6 (Table 3). Further, the scores of both scales did not differ significantly between Christians and nonreligious persons (GrAw-7: $\mathrm{F}=1.66, p=0.178 ; \mathrm{GQ}-6: \mathrm{F}=2.23 ; p=0.086$ ).

Table 3. Correlations between gratitude, wellbeing, and health behavior.

\begin{tabular}{ccc}
\hline & Gratitude/Awe (GrAw-7 Sum) & Gratitude (GQ-6 Sum) \\
\hline Gratitude/Awe (GrAw-7) & 1.000 & $\mathbf{0 . 4 1 8 ^ { * * }}$ \\
Gratitude/Awe (SpREUK-P) & $\mathbf{0 . 8 3 3 * *}$ & $\mathbf{0 . 4 7 8 ^ { * * }}$ \\
Life satisfaction (BMLSS-10) & 0.148 & $\mathbf{0 . 3 3 2}$ \\
Wellbeing (WHO-5) & $0.293^{* *}$ & $0.247^{* *}$ \\
Frequency smoking & -0.083 & -0.079 \\
Frequency alcohol consumption & -0.152 & -0.103 \\
Frequency sporting activities & 0.147 & 0.141 \\
Frequency meditation & $\mathbf{0 . 4 0 7 * *}$ & $\mathbf{0 . 3 3 2}$ \\
Frequency praying & $\mathbf{0 . 3 4 1}$ & $\mathbf{0 . 4 4 2}$ \\
Age & $0.205^{* *}$ & -0.038 \\
\hline$* * p<0.01$ (Spearman rho); moderate to strong correlations are highlighted (bold).
\end{tabular}

\subsection{Correlations between Gratitude/Awe and External Indicators}

The GrAw-7 was strongly related with SpREUK-P's 3-item Gratitude/Awe scale ( $r=0.83)$, and moderately correlated with the GQ-6 scale $(r=0.42)$. In contrast to the GQ-6, which addresses a person's grateful disposition and is moderately related to life satisfaction (BMLSS) and weakly related to wellbeing (WHO-5), the Gratitude/Awe scale is not significantly related to life satisfaction and only weakly associated with wellbeing as well (Table 3).

Neither smoking nor alcohol consumption nor sporting activities were found to be significantly related to both scales, while frequency of meditation and praying were moderately related to the GrAw-7 and the GQ-6 (Table 3).

\subsection{Predictors of Gratitude/Awe and Dispositional Gratefulness}

To analyze predictors of Gratitude/Awe (GrAw-7) and dispositional gratefulness (GQ-6), we performed regression analyses and included only those variables which were found to have some significant influences (i.e., life satisfaction, wellbeing, meditation, and praying).

As shown in Table 4, Gratitude/Awe was predicted best by meditation, with a further effect of praying, while wellbeing had a small correlation, and life satisfaction was not at all associated with Gratitude/Awe. The included variables explain $26 \%$ of variance.

In contrast, a grateful disposition was explained best by praying, followed by life satisfaction and meditation, while wellbeing had no significant effect. The included variables explain $29 \%$ of variance. 
Table 4. Regression models.

\begin{tabular}{lcccc}
\hline & $\mathbf{R}^{\mathbf{2}}$ & Beta & $\mathbf{T}$ & $\mathbf{P}$ \\
\hline $\begin{array}{l}\text { Dependent variable: GrAw-7 } \\
\text { (constant) }\end{array}$ & 0.26 & & & \\
$\quad$ Life satisfaction (BMLSS-10) & & 0.010 & 0.127 & $<0.0001$ \\
Wellbeing (WHO-5) & & 0.174 & 2.206 & 0.029 \\
Meditation & & 0.323 & 4.614 & $<0.0001$ \\
Praying & 0.29 & 0.201 & 2.815 & 0.005 \\
\hline Dependent variable: GQ-6 & & & \\
$\quad$ (constant) & & 0.278 & 3.724 & $<0.0001$ \\
Life satisfaction (BMLSS-10) & & 0.184 & -0.417 & 0.678 \\
Wellbeing (WHO-5) & & 0.345 & 4.983 & 0.008 \\
Meditation & & & & $<0.0001$ \\
Praying & &
\end{tabular}

\section{Discussion}

This study confirms that the extended version of the Gratitude/ Awe scale (GrAw-7) has good psychometric properties (Cronbach's alpha $=0.82$ ) and sound correlation with external measures, particularly with grateful disposition. Although both measures, Gratitude/ Awe (GrAw-7) and grateful disposition (GQ-6), were moderately related, they are conceptually different, as confirmed by SEM. Also, their pattern of predictors is different. While Gratitude/ Awe was best predicted by meditation practice, a grateful disposition was best predicted by praying, general life satisfaction, and meditation practice as well. Although wellbeing was weakly correlated with both variables, it was not found to be a significant predictor. The extended GrAw-7 scale focused on feelings of awe, which may be accompanied by subsequent feelings of gratefulness. These feelings of gratitude are suggested to be states of a mindful awareness rather than reciprocal gratefulness in response to the kindness of concrete persons.

Wood et al. (2008) suggested that the conceptualization of gratitude (in terms of gratitude to others) should be extended with the inclusion of having an awareness of the present moment, feelings of wondering awe, compassion, and other variables, resulting in the more general concept of 'appreciation'. This is of importance from a conceptual point of view when it is the intention to clarify the complex interplay of influencing variables resulting in 'gratitude'. However, our intention was to develop a short and circumscribed measure of wondering awe in distinct moments which may result in feelings of gratitude for life, persons, nature, etc., rather gratitude towards a concrete person providing benefits. In this sense, we understand it as a state, not as a trait. It thus does not cover the whole range of meanings implied by the term 'gratitude', but rather a specific dimension or experience which is not specifically directed to some circumscribed event or human other. It seems to be closely related to the biblical Hebrew term of "berakah", by which the Jewish faithful express that they are struck or touched here and now by God, or by God's word, act, silence, absence (Häußling 1988, p. 207). "Gratitude" in this sense permeates the religious emotivity of biblical belief. It is nourished by the amazement about God or what became an experience of God (Schimanowski et al. 1997), by numinous awe in front of God or what are considered moments of theophany (Neumann 2006). In this understanding, gratitude and awe are intrinsically connected in front of the Sacred, which can be experienced as the depth dimension (P. Tillich) of all reality (Wisse 1988). Referring to John 1,1-3, which states that God's word originated "all things", one may assume that this living "word" is still speaking through all things and beings to those who stop and listen. Experiencing this ubiquitous presence, gratitude becomes a pervasive, non-directed gratefulness.

There are two relevant other instruments which hold specific subscales addressing awe: the "Appreciation Scale" by Adler and Fagley (2005) and the "Dispositional Positive Emotions Scale" (DPES) by Shiota et al. (2006). The 57-item "Appreciation Scale" is conceptually close to our instrument, 
as it also includes subscales addressing awe, gratitude, and present moment. Fagley (2012) found that the subscales on gratitude $(r=0.70)$, present moment $(r=0.48)$, and awe $(r=0.38)$ were moderately to strongly associated with grateful disposition (GQ-6). In our study, we found that Gratitude/Awe (GrAw-7) was moderately related to grateful disposition (GQ-6: $r=0.42)$, but that Gratitude/ Awe was not significantly related to general and multidimensional life satisfaction, while a grateful disposition exhibited a moderate relation. Nevertheless, in our study both scales were only weakly related to wellbeing. Also, SEM confirmed that these concepts are distinct, despite some weak correlations.

The six-item awe subscale on "Dispositional Positive Emotions Scale" (DPES) addresses feelings of awe, feelings of wonder, seeing beauty all around, having many opportunities to see the beauty of nature, looking for patterns in objects, and seeking out experiences that challenge the individual's understanding of the world (Shiota et al. 2006). With the DPES's awe subscale, Piff et al. (2015) found awe to be associated with increased generosity and prosociality. The authors suggested that awe may "trigger an almost metaphorical sense of smallness of the self" which may be perceived when one is confronted with something "larger", i.e., a starry sky, landscapes, etc. In contrast to the DPES awe subscale, which addresses feelings of admiration of nature's beauty, the GrAw-7 scale refers more to attentional and open experiences ('mindful awareness') evoked by distinct places, nature, or specific moments, and these feelings of 'wonder' that may make a person stop and pause for a moment.

\section{Limitations}

We do not assume that the study population is representative of a 'normal' population; the snowball sampling strategy obviously resulted in a dominance of persons with a high school education. For the validation process this is not of major relevance, but for future studies a more balanced sample would be required.

\section{Conclusions}

The seven-item Gratitude/Awe (GrAw-7) scale was confirmed as a short, reliable, and valid measure with good psychometric properties (Cronbach's alpha $=0.82$ ) and a sound correlation with grateful disposition. The scale is not contaminated with specific religious topics or quality of life issues. Because of its brevity, it can be easily implemented in larger studies to measure different aspects of spirituality also in secular societies. This attitude can probably also be found in a-religious persons and could be seen as a measure of 'mindful awareness' in terms of nonreligious (secular) spirituality.

Acknowledgments: There was no external funding for this study. We are grateful to all who have filled the questionnaire.

Author Contributions: AB has designed the questionnaire, has analyzed the data and written the manuscript. DRR has performed the SEM analyzed and contributed to write the manuscript. KB contributed in writing the manuscript. All authors approved the final version of the manuscript.

Conflicts of Interest: The authors declare no conflict of interest.

\section{References}

Adler, Mitchel G., and Nancy S. Fagley. 2005. Appreciation: Individual Differences in Finding Value and Meaning as a Unique Predictor of Subjective Well-Being. Journal of Personality 73: 79-114. [CrossRef] [PubMed]

Algoe, Sara B., and Jonathan Haidt. 2009. Witnessing excellence in action: The "other-praising" emotions of elevation, gratitude, and admiration. Journal of Positive Psychology 4: 105-27. [CrossRef] [PubMed]

Algoe, Sara B., and Annette L. Stanton. 2012. Gratitude When It Is Needed Most: Social Functions of Gratitude in Women with Metastatic Breast Cancer. Emotion 12: 163-68. [CrossRef] [PubMed]

Bech, Per, Lis Raabaek Olsen, Mette Kjoller, and Niels Kristian Rasmussen. 2003. Measuring well-being rather than the absence of distress symptoms: A comparison of the SF-36 mental health subscale and the WHO-Five well-being scale. International Journal of Methods in Psychiatric Research 12: 85-91. [CrossRef] [PubMed] 
Büssing, Arndt, Peter F. Matthiessen, and Thomas Ostermann. 2005. Engagement of patients in religious and spiritual practices: Confirmatory results with the SpREUK-P 1.1 questionnaire as a tool of quality of life research. Health and Quality of Life Outcomes 3: 53. [CrossRef] [PubMed]

Büssing, Arndt, Julia Fischer, Almut Haller, Thomas Ostermann, and Peter F. Matthiessen. 2009. Validation of the Brief Multidimensional Life Satisfaction Scale in patients with chronic diseases. European Journal of Medical Research 14: 171-77. [CrossRef] [PubMed]

Büssing, Arndt, Franz Reiser, Andreas Michalsen, and Klaus Baumann. 2012. Engagement of patients with chronic diseases in spiritual and secular forms of practice: Results with the shortened SpREUK-P SF17 Questionnaire. Integrative Medicine: A Clinician's Journal 11: 28-38.

Büssing, Arndt, Ane-Gritli Wirth, Franz Reiser, Anne Zahn, Knut Humbroich, Kathrin Gerbershagen, Sebastian Schimrigk, Michael Haupts, Niels Christian Hvidt, and Klaus Baumann. 2014. Experience of gratitude, awe and beauty in life among patients with multiple sclerosis and psychiatric disorders. Health and Quality of Life Outcomes 12: 63. [CrossRef] [PubMed]

Büssing, Arndt, Eckhard Frick, Christoph Jacobs, and Klaus Baumann. 2017. Self-Attributed Importance of Spiritual Practices in Catholic Pastoral Workers and their Association with Life Satisfaction. Pastoral Psychology 66: 295-310. [CrossRef]

Emmons, Robert A., and Cheryl A. Crumpler. 2000. Gratitude as a human strength: Appraising the evidence. Journal of Social and Clinical Psychology 19: 56-69. [CrossRef]

Fagley, Nancy S. 2012. Appreciation uniquely predicts life satisfaction above demographics, the Big 5 personality factors, and gratitude. Personality and Individual Differences 53: 59-63. [CrossRef]

Häußling, Angelus. 1988. Dank/Dankbarkeit. In Praktisches Lexikon der Spiritualität. Edited by Christian Schütz. Freiburg: Herder, pp. 205-8.

Hill, Patrick L., and Mathias Allemand. 2011. Gratitude, Forgiveness, and Well-Being in Adulthood: Tests of Moderation and Incremental Prediction. The Journal of Positive Psychology 5: 397-407. [CrossRef]

Keltner, Dacher, and Jonathan Haidt. 2003. Approaching awe, a moral, spiritual, and aesthetic emotion. Cognition and Emotion 17: 297-314. [CrossRef]

McCullough, Michael E., Robert A. Emmons, and Jo-Ann Tsang. 2002. The grateful disposition: A conceptual and empirical topography. Journal of Personality and Social Psychology 82: 112-27. [CrossRef] [PubMed]

Neumann, Klaus. 2006. Ehrfurcht. In Handbuch Theologischer Grundbegriffe zum Alten und Neuen Testament. Edited by Angelika Berlejung and Christian Frevel. Darmstadt: Wissenschaftliche Buchgesellschaft, pp. 140-41.

Pearsall, Paul. 2007. Awe: The Delights and Dangers of Our Eleventh Emotion. Deerfield Beach: Health Communications Inc., ISBN 978-0-7573-0585-6.

Pettinelli, Mark. 2014. The Psychology of Emotions, Feelings and Thoughts. OpenStax-CNX Module: m14358. Available online: https://cnx.org/contents/vsCCnNdd@130/The-Psychology-Of-Emotions-Fee (accessed on 20 February 2018).

Piff, Paul K., Pia Dietze, Matthew Feinberg, Daniel M. Stancato, and Dacher Keltner. 2015. Sublime sociality: How awe promotes prosocial behavior through the small self. Journal of Personality and Social Psychology 108: 883-99. [CrossRef] [PubMed]

Schimanowski, Gottfried, Helmut Schultz, Hans Helmut Eßer, Karl Heinz Bartels, and Jürgen Fangmeier. 1997. Dank/Lob. In Theologisches Begriffslexikon zum Neuen Testament. Edited by Lothar Coenen and Klaus Haacker. Wuppertal: R. Brockhaus Verlag, pp. 239-51.

Shiota, Michelle N., Dacher Keltner, and Oliver P. John. 2006. Positive emotion dispositions differentially associated with Big Five personality and attachment style. Journal of Positive Psychology 1: 61-71. [CrossRef]

Shiota, Michelle N., Dacher Keltner, and Amanda Mossman. 2007. The nature of awe: Elicitors, appraisals, and effects on self-concept. Cognition and Emotion 21: 944-63. [CrossRef]

Stellar, Jennifer F., Amie M. Gordon, Paul K. Piff, Daniel Cordaro, Craig L. Anderson, Yang Bai, Laura A. Maruskin, and Dacher Keltner. 2017. Self-Transcendent Emotions and Their Social Functions: Compassion, Gratitude, and Awe Bind Us to Others through Prosociality. Emotion Review 9: 200-7. [CrossRef]

Whiting, Demian. 2011. The Feeling Theory of Emotion and the Object-Directed Emotions. European Journal of Philosophy 19: 281-303. [CrossRef] 
Wisse, Stephan. 1988. Ehrfurcht. In Praktisches Lexikon der Spiritualität. Edited by Christian Schütz. Freiburg: Herder, pp. 267-69.

Wood, Alex M., John Maltby, Neil Stewart, and Stephen Joseph. 2008. Conceptualizing gratitude and appreciation as a unitary personality trait. Personality and Individual Differences 44: 619-30. [CrossRef] 